\title{
Numerical investigation on methane hydrate accumulation in Shenhu Area, northern continental slope of South China Sea
}

\author{
Zheng Su ${ }^{\mathrm{a}, \mathrm{b}, *}$, Yuncheng Cao ${ }^{\mathrm{a}, \mathrm{c}}$, Nengyou $\mathrm{Wu}^{\mathrm{a}, \mathrm{b}}$, Duofu Chen ${ }^{\mathrm{a}, \mathrm{c}}$, Shengxiong Yang ${ }^{\mathrm{d}}$, Hongbin Wang ${ }^{\mathrm{d}}$ \\ ${ }^{a}$ Guangzhou Center for Gas Hydrate Research, Chinese Academy of Sciences, Guangzhou, China \\ ${ }^{\mathrm{b}}$ Key Laboratory of Renewable Energy and Gas Hydrate, Guangzhou Institute of Energy Conversion, Chinese Academy of Sciences, Guangzhou, China \\ ${ }^{\mathrm{c}}$ Key Laboratory of Marginal Sea Geology, Guangzhou Institute of Geochemistry, Chinese Academy of Sciences, Guangzhou, China \\ ${ }^{\mathrm{d}}$ Guangzhou Marine Geological Survey, Guangzhou, China
}

\section{A R T I C L E I N F O}

\section{Article history:}

Received 24 August 2011

Received in revised form

21 April 2012

Accepted 11 June 2012

Available online 20 June 2012

\section{Keywords:}

Shenhu Area

Gas hydrate

Hydrate formation

Hydrate saturation

Numerical modeling

\begin{abstract}
A B S T R A C T
The hydrate deposits in Shenhu Area on northern continental slope of the South China Sea is regarded as one of the promising targets for gas hydrate exploration and exploitation in China. The hydrates concentrate at base of gas hydrate stability zone (GHSZ) with a peak saturation of $48 \%$. However, the formation mechanism and controlling factors of the hydrates remain unclear. Previous studies suggested that sedimentation flux and water flux are two fundamental parameters controlling hydrate accumulation. Here, we have applied a one-dimensional dynamic model to characterize the hydrate evolution pattern at a drilling site of SH2 in Shenhu Area. The hydrate saturations modeled at current sedimentation rate and water flow rate were much different from the values approved. Some perturbations of the two parameters seemed to be useless to improve the modeling. The big finding was that the modeled result basically matched the saturation values at initial hydrate saturations of $20-22 \%$. The results indicated that massive gas hydrates formed in the early fractured sediment in Shenhu Area, the sediment evolved by inheriting the "ancient" hydrate and lasted for $\sim 1.5$ Myrs before present and produces the current hydrate feature. The modeling implies that resource potential of Shenhu hydrate has been decreasing.
\end{abstract}

(C) 2012 Elsevier Ltd. All rights reserved.

\section{Introduction}

Gas hydrates are crystalline substances composed of water and gas, in which a solid water lattice accommodates gas molecules in a cage-like structure. Natural gas hydrates in geological systems mainly contain $\mathrm{CH}_{4}$, although natural gas hydrate may also form with $\mathrm{CO}_{2}, \mathrm{H}_{2} \mathrm{~S}$ and $\mathrm{N}_{2}$ (Sloan, 1998). Natural gas hydrates can form in marine sediment of low temperatures $(T)$ and high pressures $(P)$ when gas concentrations exceed the solubility in the solutions at appropriate stability conditions (Davie and Buffett, 2003a). The depth interval appropriate for sub-bottom gas hydrate formation is confined by the combination of temperature and pressure, and is commonly called the GHSZ (Rempel and Buffett, 1997). Natural gas hydrates are generally occurred in permafrost regions and beneath the seafloor where thermodynamic conditions are suitable for hydrate formation (Milkov, 2004).

\footnotetext{
* Corresponding author. Guangzhou Center for Gas Hydrate Research, Chinese Academy of Sciences, 2 Nengyuan Rd, Wushan, Tianhe, Guangzhou, China.

E-mail address: suzheng@ms.giec.ac.cn (Z. Su).
}

Because of their potential importance as an energy resource (Collett, 2002), greenhouse gas sinks (Milkov and Sassen, 2003), large component of the global carbon cycle (Dickens, 2003), and marine geologic disaster (Sultan et al., 2004), hydrates are currently attracting significant attentions and have been extensively investigated around the world (Milkov, 2004). A good appreciation of these issues requires an understanding of how gas hydrates accumulate in marine sediment sequences over time (Bhatnagar et al., 2007). Dynamics of some hydrate accumulations around the world have been numerically researched (e.g. Xu and Ruppel, 1999; Chen and Cathles, 2003; Liu and Flemings, 2006, 2007; Bhatnagar et al., 2007).

The northern continental slope of the South China Sea (SCS) is among the most important fields for marine hydrate investigations, where Shenhu Area is one of the most promising blocks (Fig. 1). Geophysical, geological, geothermal, and geochemical investigations have suggested that Shenhu Area is a favorable place for gas hydrates (Wu et al., 2009, 2010). Eight sites were selected for drilling and sampling in the Area, and in the meantime core samples were collected (Fig. 1). Depressurization experiments verified the existence of methane hydrates in the clay silt sediment 


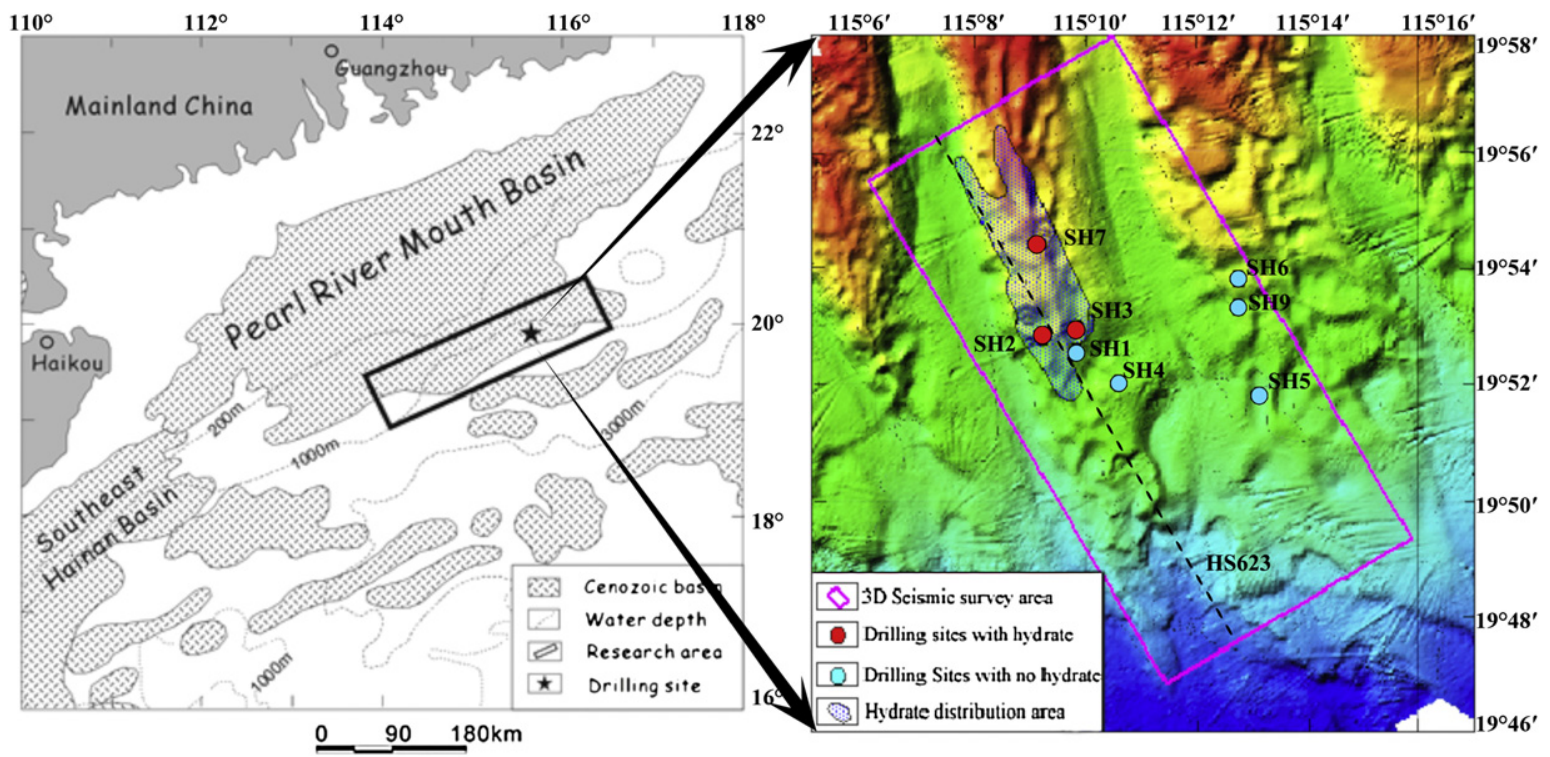

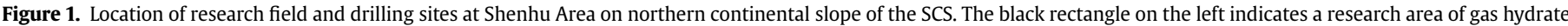

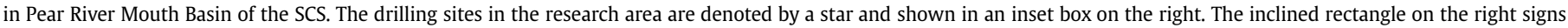
a 3D seismic survey area for selecting drilling sites. The black dash line is seismic profile HS623 (see Fig. 3)

cores taken at sites $\mathrm{SH} 2, \mathrm{SH} 3$, and $\mathrm{SH} 7$ at the water depth of 1108-1235 m (Wu et al., 2009, 2010).

Chloride analysis of porewater from the depressurized samples shows the hydrate saturation is up to $\sim 48 \%$ at the drilling site $\mathrm{SH} 2$ and the hydrates concentrate at base of the GHSZ (Wu et al., 2010). The abnormal feature differs from that of a typical hydrate deposit in fine-grained sediment basin. The saturation distribution and the values were critically doubted for the paucity and discontinuity of the core samples, and logging data was then used to evaluate the hydrate saturations (Wang et al., 2011; Fig. 2).

The mechanism of hydrate accumulation in Shenhu Area has been not yet clearly understood. Wu et al. (2009) demarcated the

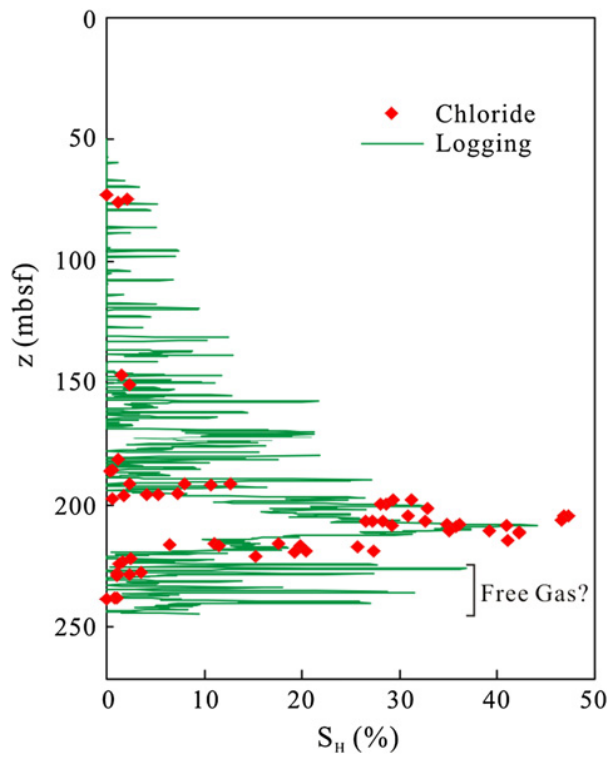

Figure 2. Hydrate saturations at the drilling site $\mathrm{SH} 2$. The red spots denote the hydrate saturations calculated by the chloride deviations (Wu et al., 2010), the solid line shows the hydrate saturations computed by the logging data (Wang et al., 2011). The values of big differences at base of the data are doubted to indicate free gas. (For interpretation of the references to colour in this figure legend, the reader is referred to the web version of this article.)
GHSZ and predicted the resource potential. Guan et al. (2009) simulated the hydrate development using a gas-venting model. The authors proposed that Shenhu hydrate was controlled by a migration of free gas venting through the GHSZ. However, free gas has not been directly detected in the sediment, and the geological setting was not considered in the modeling.

Former studies suggested that for a fine-grained sediment containing dispersed hydrates, e.g. Shenhu deposits, the most crucial factors controlling hydrate accumulation are sedimentation rate and gas flux into GHSZ (e.g., Davie and Buffett, 2001). Flux of dissolved gas depends on methane advection and diffusion in aqueous solution, and in-situ methanogenesis by degradation of organic matter. If contribution of advection to methane flux is dominant, gas flux can be approximately represented by water flux and methane concentration. Thus hydrate formation in GHSZ is determined by water flow rate for an invariable methane concentration. Sedimentation means a move down of sediment containing solid hydrates and thus has negative effects on hydrate preservation and growth (Davie and Buffett, 2001; Bhatnagar et al., 2007).

The purpose of this study is to establish a dynamic model for gas hydrate accumulation in a GHSZ to explore how sedimentation and water flow control gas hydrate development, and to reveal a reasonable course of gas hydrate evolution in Shenhu Area. In what follows we will introduce a quantitative models based on geological study and principles for hydrate formation in natural systems.

\section{Geological setting}

The Shenhu hydrate field is near southeast of Shenhu Underwater Sandy Bench at middle of northern continental slope of the SCS (Fig. 1). Tectonically, the research area is located in the Zhu II Depression, Pearl River Mouth Basin, which has been in process of tectonic subsidence since the middle Miocene and created geologic conditions for gas hydrate formation (Wu et al., 2009). Oil and gas are produced from deeper reservoirs in the Area.

The Shenhu basin includes 1000-7000 m thick sediment, with organic matter contents of $0.2-1.9 \%$ (Wang et al., 2000; McDonnell et al., 2000; Wu et al., 2009). The organic matter contents is generally low at shallow depth but relatively high in deep sediment 
(Wang et al., 2000), which implies that contribution of in-situ biogenic methane at shallow depth to hydrate formation is small and hydrate-forming gas is dominantly deep source methane. Clay and silt are dominant in the sediment samples and seep carbonates have not been observed. Thus free gas seeping might not happen in the geologic history penetrated through by the borehole and pore fluid in the sediment is unsaturated by methane gas.

Faults on northern continental slope of the SCS mainly include NEE (or NE) and NW strikes. The former are tensional faults while the later are transtensional faults, and both have good hydraulic conductivities ( $\mathrm{Wu}$ et al., 2009). The faulting activities were extremely intensive during the late Pliocene - early Pleistocene in Shenhu Area. The latest faulting activity happened at time interval of 2.0-1.5 million year before present, and formed mainly NE strike faults, traps and huge mud diapers. The faults also derived many pinnate arranging faults (Fig. 3; Wu et al., 2009).

\section{Mathematical model}

The numerical model for simulating gas hydrate accumulation in Shenhu Area consists of three main parts: (1) calculating sedimentation rate, (2) calculating water flow rate, and (3) simulating hydrate formation by mass balance equation of methane.

\subsection{Sedimentation rate}

In geologic time scale sedimentation leads to sediment compaction. Sediment porosity below seafloor is related to vertical effective stress in the compaction theory (Terzaghi, 1943; Gibson, 1958). For one-dimensional compaction, porosity $(\phi)$ can be written as a function of the effective stress or burial depth. In this model the porosity is assumed to be in steady state and of the form (Athy, 1930; Haacke et al., 2008):

$\phi=\phi_{0} e^{-z / \lambda}$,

where $\lambda$ is the compaction length and $\phi_{0}$ is the seabed porosity. The compaction length reflects physical properties of seabed sediments, and its value can be fitted by porosity values measured.

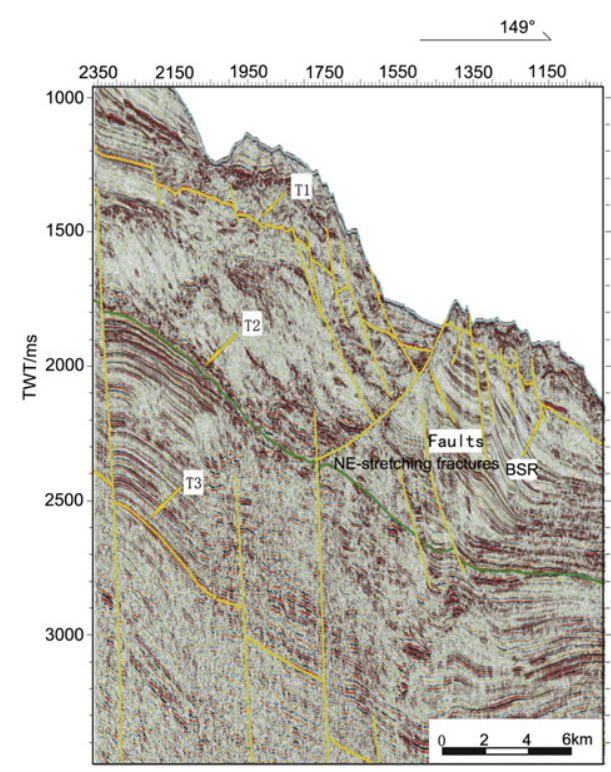

Figure 3. The seismic profile HS623 showing the NE-stretching fractures in Shenhu Area. Two fracture groups with opposite dips indicate the fluid migration system of the Shenhu sediment (Wu et al., 2009).
The porosity-depth relation along with mass balances for sediment provides an expression for the sediment flux (Berner, 1980; Xu and Ruppel, 1999; Davie and Buffett, 2001). The sediment balance can be written as:

$\frac{\partial}{\partial t}(1-\phi) \rho_{s}+\nabla \cdot\left[v_{s} \rho_{s}(1-\phi)\right]=0$,

where $\rho_{s}$ is sediment density, and $v_{s}$ is the sediment velocity. Assuming steady state leads to invariant sediment flux $\left(U_{S}\right)$ with depth, which can be related to sedimentation rate $(S)$ as a boundary condition imposed at seafloor (Berner, 1980). If porosity $\phi$ is in a steady state in vertical direction and sediment density $\rho_{s}$ is constant, the term $(1-\phi) \rho_{s}$ in the equation is invariant over time, which drives the second term $\nabla \cdot\left[v_{s} \rho_{s}(1-\phi)\right]=0$. Then an equation of invariant sedimentation flux is drawn as (Bhatnagar et al., 2007):

$U_{S}=v_{S}(1-\phi)=S\left(1-\phi_{0}\right)$,

$U_{S}$ is invariant sedimentation flux, $S$ is depositional rate at seafloor. Sedimentation rate $v_{s}$ can be calculated as a function of porosity.

\subsection{Water flow rate}

Anaerobic oxidation of methane (AOM) in marine sediments is a complex biogeochemical process (Hinrichs and Boetius, 2002; Joye et al., 2004; Treude et al., 2005). The upward methane gas is oxidized by the downward diffusing sulfate in shallow depths, leading to sharp decline in sulfate and methane contents. The AOM mainly occurs at sulfate-methane interface (SMI, where methane and sulfate are consumed and transformed to biocarbonate and hydrogen sulfide $\left(\mathrm{HS}^{-}\right)$, and the biogeochemical processes is: $\mathrm{CH}_{4}+\mathrm{SO}_{4}^{2-} \rightarrow \mathrm{HCO}_{3}^{-}+\mathrm{HS}^{-}+\mathrm{H}_{2} \mathrm{O}$ (Hinrichs and Boetius, 2002; Joye et al., 2004; Treude et al., 2005).

Methane concentration at depth of SMI at hydrate field in Shenhu Area is close to zero (Wu et al., 2010), indicating that methane migrating upwards is almost completely consumed by sulfate diffusing downwards from seawater. Methane and sulfate reach a reactive equilibrium at the SMI depth. Methane gas dissolving in pore water migrates in forms of convection and diffusion, and sulfate transmits mainly in form of diffusion indicated by straight lines of concentration, thus the equilibrium equation is:

$q_{w} \rho_{f} c_{m}^{l}-D_{m} \frac{\partial c_{m}^{l}}{\partial z}-D_{s} \frac{\partial c_{s}^{l}}{\partial z}=0$.

in which $q_{w}$ is fluid flow rate, $\rho_{f}$ is pore fluid density, $c_{m}^{l}$ and $c_{s}^{l}$ are methane and sulfate concentrations in the liquid, $D_{m}$ and $D_{s}$ are diffusion coefficients of methane and sulfate in the liquid phase, respectively.

\subsection{Equilibrium formation of hydrate}

Numerical model of hydrate formation includes methane solubility equations and conservation equations of mass and energy in a marine sediment system. Methane solubility curves demarcate GHSZ, and define a minimum concentration of methane in fluid required for hydrate crystallizing within the GHSZ and thus control hydrate accumulation process. Conservation of mass explains conversion of methane between different phases.

Hydrate distribution in subsurface sediments depends on two P-T dependent equilibrium solubility curves: the liquid-hydrate $(\mathrm{L}+\mathrm{H})$ methane solubility curve and the liquid-gas $(\mathrm{L}+\mathrm{G})$ methane solubility curve. Gas hydrate is in equilibrium with dissolved gas in water and free gas is absent for the $\mathrm{L}+\mathrm{H}$ curve. For the 
$\mathrm{L}+\mathrm{G}$ curve, free gas is in equilibrium with dissolved gas in water and hydrate is absent (Liu and Flemings, 2006). The model by Duan et al. (1992) is used in this study to predict the $L+G$ equilibrium. The methane solubility in $\mathrm{L}+\mathrm{H}$ equilibrium is fitted as a function of temperature and salinity (Su and Chen, 2007):

$S_{m}^{l}=\left(0.0025 T^{2}+0.0628 T+1.083\right)(1-0.1 \cdot Y) \exp \left(\frac{T-\mathrm{T}^{*}}{14.5}\right)$

Hydrate forms when $S_{m}^{l}$ of methane hydrate solubility is exceeded by $c_{m}^{l}$ of methane concentration in aqueous solution. $T^{*}$ denotes temperature at base of GHSZ, $T$ is temperature within GHSZ, $Y$ is pore water salinity in molarity (Davie et al., 2004).

Mass balance equation of methane decides distribution and conversion of methane in the phases. Free gas will not involved in model for simplicity, because free gas is absent within GHSZ and sparse below GHSZ in Shenhu area. Methane migrates in form of dissolved gas from deep. In-situ generation of methane is neglected for the poor organic content in shallow depth in Shenhu Area. Methane balance equation in one-dimension can be written as:

$\frac{\partial(\rho \varphi C)}{\partial t}+\frac{\partial}{\partial z}\left[q_{w} c_{m}^{l} \rho_{f}+U_{s} \frac{\varphi}{1-\varphi} S_{h} \rho_{h} c_{m}^{h}-\varphi\left(1-S_{h}\right) D_{m} \rho_{f} \frac{\partial c_{m}^{l}}{\partial z}\right]=0$.

In Equation (6) denotes density of substances in sediment pores, $\rho=S_{l} \rho_{l}+S_{h} \rho_{h} \cdot \rho_{l}$ and $\rho_{h}$ and $\rho_{h}$ are densities of liquid and hydrate, respectively. $S_{l}$ and $S_{h}$ respectively denote liquid and hydrate saturations, $S_{l}+S_{h}=1$. $c_{m}^{h}$ is mass fraction of methane in hydrate, $c_{m}^{h}=0.129 \cdot U_{s}$ and $q_{w}$ represent respectively sedimentation flux and net water flow rate. Equation (6) indicates that hydrate accumulation depends on sedimentation rate and water flow rate.

\section{Application to Shenhu Area}

At the site SH2 in Shenhu Area, water depth is $1235 \mathrm{~m}$, water salinity is $33.4 \%$, bottom water temperature is $3.8{ }^{\circ} \mathrm{C}$, and average temperature gradient in the seafloor sediment is $0.047^{\circ} \mathrm{C} / \mathrm{m}$. Over $99 \%$ of the hydrate gas is methane. The SMI depth at this site is 27 mbsf. By comparison hydrate saturations calculated by porewater salinity and logging data (Wu et al., 2010; Wang et al., 2011), top depth of the hydrate zone is determined to be $72 \mathrm{mbsf}$, and the hydrate saturation ranges from 0 to $48 \%$. The data above will be employed to model the dynamics of hydrate accumulation in Shenhu Area. The modeled results will be compared with the estimations by chloride and logging in Figure 2.

\subsection{Sedimentation rate}

Sedimentation over geologic time leads to porosity changes and downward shifts of sediment. Porosity below seafloor decreases exponentially with depth as defined in Equation (1). By fitting porosity values of cores sampled at the site $\mathrm{SH} 2$, we know $\phi_{0}=0.55898$, and $\lambda=524 \mathrm{~m}$. The porosity can be expressed as $\phi=0.55898 e^{-0.0019 \cdot Z}$ and shown in Figure 4 (solid line). Sedimentation rate is related to porosity and seafloor sedimentation rate (Equation 3).

The sediment depositional rate at seafloor was $10-20 \mathrm{~cm} / \mathrm{kyr}$ in the history penetrated by the borehole of $\mathrm{SH} 2$ and especially equal to $20 \mathrm{~cm} / \mathrm{kyr}$ in the latest 1.2 Myrs. Average seafloor sedimentation rate was $16 \mathrm{~cm} / \mathrm{kyr}$ for a simulated domain of $250 \mathrm{~m}$ thick beneath seafloor. The vertical distribution of sedimentation rate is

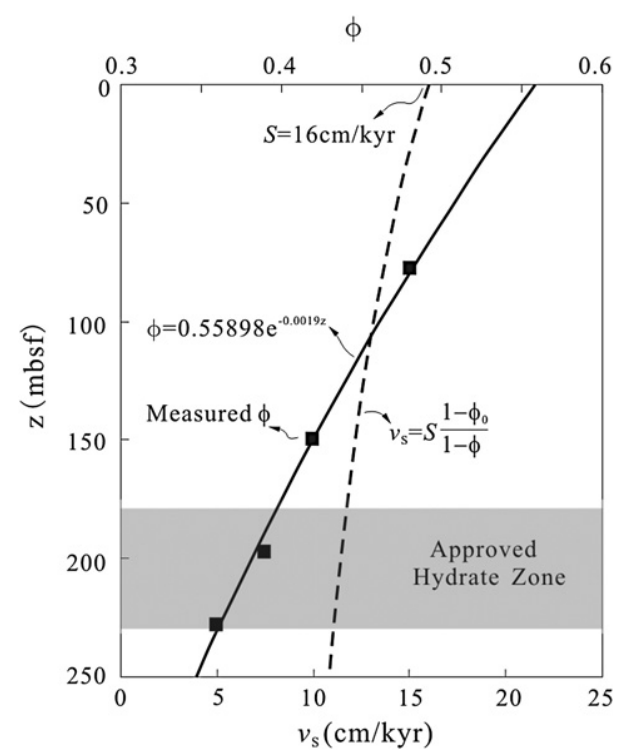

Figure 4. One-dimensional distribution of sedimentation rate and porosity at site $\mathrm{SH} 2$. The solid line denotes the porosity profile and the dash line denotes sedimentation rate profile. The approved hydrate zone is confined by chloride deviations and depressurization analysis (Wu et al., 2010).

calculated by using Equation (3) and shown in Figure 4 as a dotted line. The sedimentation rate is $\sim 11 \mathrm{~cm} / \mathrm{kyr}$ at base of GHSZ, which indicates that the sediment moves downwards and hydrate at the base of GHSZ becomes unstable at the rate. By using the average seafloor sedimentation rate, the maximal age of the hydrate layer $t_{b}=\int_{0}^{229} d z / v_{s}=1.58 \mathrm{Ma}$, approaching the end of last tectonic activity (2.0-1.5 Ma). The temporal relation may imply that the hydrates have been developed at the end of tectonic activity in the fractured system.

\subsection{Water flow rate}

Another important parameter for investigating the evolution of gas hydrate reservoir is upward migration rate of gas-rich fluid (hereafter water flow rate) in sediment. The upward flow of deep fluids promote the precipitation of hydrate (Bhatnagar et al., 2007; $\mathrm{Xu}$ and Ruppel, 1999). For a constant gas concentration in pore water beneath GHSZ, gas flux into GHSZ is determined by water flow rate, a higher water flow rate means more gas can be transferred into GHSZ and precipitated as methane hydrate.

Depth to the bottom of GHSZ is 229 mbsf pointed by an intersection of methane solubility in vapor-liquid equilibrium and methane solubility in liquid-hydrate equilibrium, coinciding with the bottom of hydrate zone (Fig. 5). Hydrate formation is confined by methane solubility in the GHSZ but the accumulation pattern depends on concentration of methane dissolved in the pore fluid. Methane concentration is equal to methane solubility in hydrate zone and lower than solubility at shallow depth. The dynamic accumulation of hydrate is fundamentally determined by gas flux into the GHSZ. Gas diffusion in GHSZ is constrained by methane solubility and boundary conditions at seafloor. Therefore water flow rate is the key factor controlling the hydrate growth.

Based on models of methane solubility, methane concentration, and SMI depth, the modeled water flow rate is $0.7 \mathrm{~m} / \mathrm{kyr}$. This value is similar to the water flow rate of $0.3-2 \mathrm{~m} / \mathrm{kyr}$ used for simulating hydrate accumulation at site ODP997 on Blake Ridge offshore South Carolina (Xu and Ruppel, 1999), but greater than that of $0.23 \mathrm{~m} / \mathrm{kyr}$ modeled by pore water sulfate at site ODP997 (Davie and Buffett, 


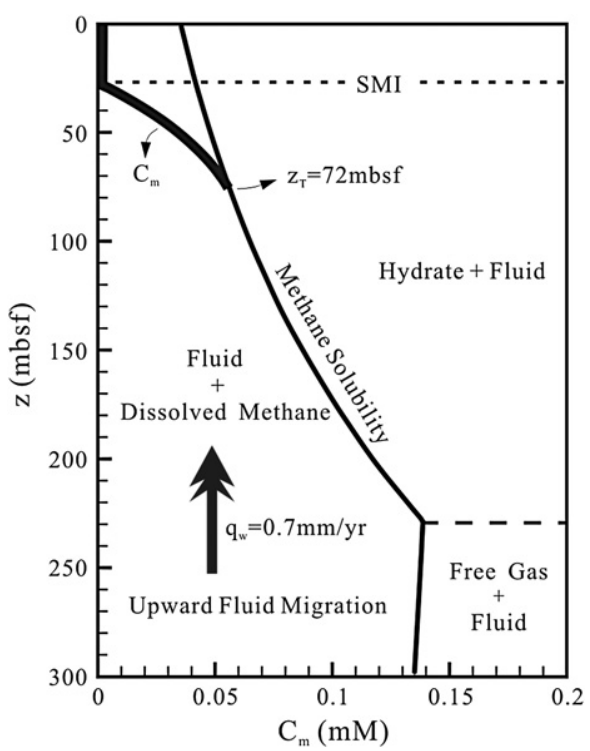

Figure 5. Profiles of methane solubility and concentration below the seafloor at site SH2. The SMI depth is 27 mbsf and the top of hydrate zone is at 72 mbsf in the model. The water flow rate is modeled to be $0.7 \mathrm{~mm} / \mathrm{yr}$.

2003b). The sediment grains at site $\mathrm{SH} 2$ are slightly coarser than that at site ODP997 (Ginsburg et al., 2000). Thus it is reasonable to mention that water flow rate at Shenhu is relatively higher.

\subsection{Hydrate formation at the conditions}

In the modeling, simulations are operated under the conditions of constant seafloor sedimentation rate and water flow rate for exploration of the hydrate evolution at drilling site SH2 in Shenhu Area. The model results can be assessed by comparing modeled envelopes with the hydrate saturations calculated previously (Wu et al., 2010; Wang et al., 2011). The values of boundary conditions and parameters selected for the modeling are listed in Table 1.

Figure 6 illustrates hydrate accumulation at the constant seafloor depositional rate of $16 \mathrm{~cm} / \mathrm{kyr}$ and the water flow rate of $0.7 \mathrm{~m} / \mathrm{kyr}$. Hydrate saturation continually builds up and reaches equilibrium in 1.3 Myrs. The saturation becomes balanced preferentially at the top and shifts toward the bottom, and does not change any more when the system gets balanced. The steady state indicates the positive contribution of water flow rate just counteracts the negative contribution of sedimentation to hydrate formation. The hydrate evolution modeled at the parameters is consistent with the previous researches (Davie and Buffett, 2003b; Bhatnagar et al., 2007).

Table 1

Site-specific parameters for site SH2 in Shenhu Area of SCS.

\begin{tabular}{llll}
\hline Symbol & Parameter & Value & Units \\
\hline$D_{\mathrm{w}}$ & Water depth & 1235 & $\mathrm{~m}$ \\
$T_{0}$ & Seafloor temperature & 3.4 & ${ }^{\circ} \mathrm{C}$ \\
$T_{\mathrm{G}}$ & Geothermal gradient & 0.047 & ${ }^{\circ} \mathrm{C} / \mathrm{m}$ \\
$S$ & Seafloor sedimentation rate & 16 & $\mathrm{~cm} / \mathrm{kyr}$ \\
$X$ & Pore water chloride & 0.54 & $\mathrm{mM}$ \\
$z_{\mathrm{SMI}}$ & SMI depth & 27 & $\mathrm{mbsf}$ \\
$z_{T}$ & Depth to top of hydrate zone & 72 & $\mathrm{mbsf}$ \\
$z_{B}$ & Depth to base of hydrate zone & 229 & $\mathrm{mbsf}$ \\
$q_{w}$ & upward fluid flow rate & 0.14 & $\mathrm{~mm} / \mathrm{yr}$ \\
$D_{\mathrm{m}}$ & diffusion coefficient of methane & $0.87 \times 10^{-9}$ & $\mathrm{~m}^{2} / \mathrm{s}$ \\
$D_{\mathrm{s}}$ & diffusion coefficient of sulfate & $0.56 \times 10^{-9}$ & $\mathrm{~m}^{2} / \mathrm{s}$ \\
$D_{\mathrm{c}}$ & diffusion coefficient of chloride & $1.01 \times 10^{-9}$ & $\mathrm{~m}^{2} / \mathrm{s}$ \\
\hline
\end{tabular}

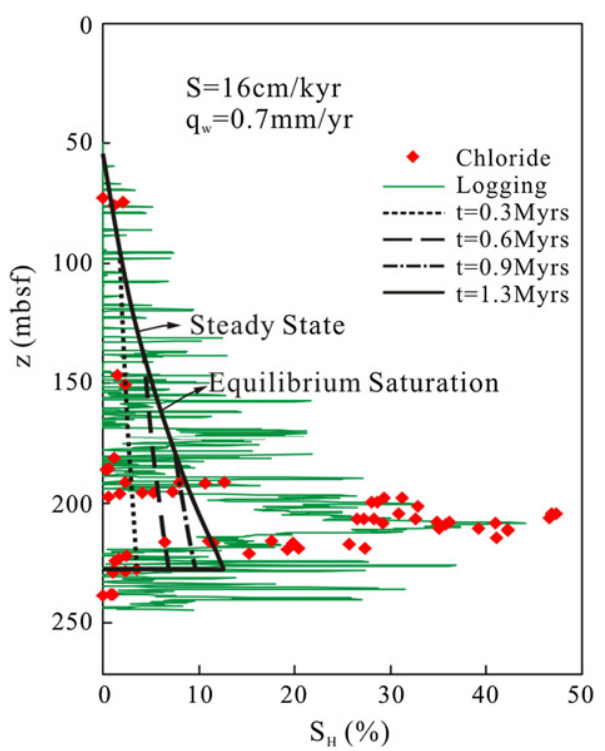

Figure 6. Hydrate accumulation at the constant seafloor depositional rate and water flow rate. The hydrate saturation reaches equilibrium in 1.3 Myrs at seafloor depositional rate of $16 \mathrm{~cm} / \mathrm{kyr}$ and water flow rate of $0.7 \mathrm{~m} / \mathrm{kyr}$.

However, the hydrate saturations modeled in Figure 6 is significantly lower than those calculated by chloride and logging data. The maximum hydrate saturation at bottom of the equilibrium curve is $13 \%$, the number is much smaller than the peak value of $48 \%$ calculated by chlorides ( $\mathrm{Wu}$ et al., 2010). The modeling results suggest that the hydrate accumulation can not be reproduced by using the two parameters observed currently. A further refinement of the suitability of the values in the model is needed.

\subsubsection{Effect of sedimentation to hydrate accumulation}

Hydrate growth at the site $\mathrm{SH} 2$ was impeded by the rapid sedimentation. In Figure 7, the simulations was redone at the water flow rate of $0.7 \mathrm{~m} / \mathrm{kyr}$ and small sedimentation rates of $4 \mathrm{~cm} / \mathrm{kyr}$, $8 \mathrm{~cm} / \mathrm{kyr}$ and $12 \mathrm{~cm} / \mathrm{kyr}$. The curves of equilibrium hydrate

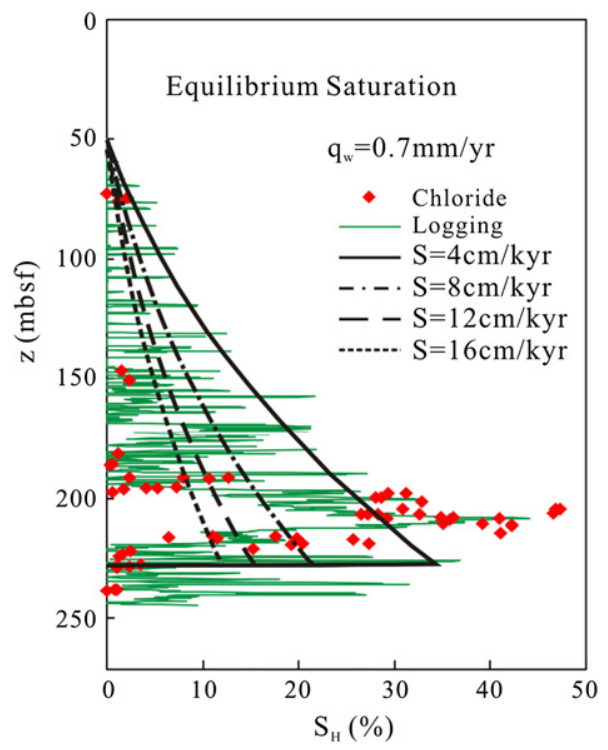

Figure 7. Effect of sedimentation rate to hydrate accumulation at the constant water flow rate of $0.7 \mathrm{~m} / \mathrm{kyr}$. The equilibrium hydrate saturations at seafloor depositional rates of $4 \mathrm{~cm} / \mathrm{kyr}, 8 \mathrm{~cm} / \mathrm{kyr}, 12 \mathrm{~cm} / \mathrm{kyr}$, or $16 \mathrm{~cm} / \mathrm{kyr}$ are less than the hydrate contents determined by Chloride and Logging. 
saturations were compared with the reference case at the sedimentation rates of $16 \mathrm{~cm} / \mathrm{kyr}$. Reductions in seafloor sedimentation rate can increase hydrate growth at the water flow rate and improve the simulation. The curve of equilibrium hydrate saturation at seafloor sedimentation rate of $4 \mathrm{~cm} / \mathrm{kyr}$ can completely cover the saturation values at shallow zone, but evidently smaller than the values at deep zone. The result indicates that the modeling can not reproduce the hydrate accumulation at site $\mathrm{SH} 2$ by altering the sedimentation rate.

\subsubsection{Effect of water flow rate to hydrate accumulation}

In the model hydrate growth is related to water flow rate. For a given methane concentration in pore fluids below GHSZ, water flow rate determines methane supply into the GHSZ and hydrate conversion. A high water flow rate promotes hydrate accumulation, while a small water flow rate impairs methane supply and even incurs hydrate dissolution.

Figure 8 shows the equilibrium hydrate saturations at the fixed seafloor sedimentation rate of $16 \mathrm{~cm} / \mathrm{kyr}$ and altered water flow rates ranging $0.3-2.0 \mathrm{~mm} / \mathrm{yr}$ (Xu and Ruppel, 1999). The hydrate saturations at steady states get smaller at water flow rate of $0.3 \mathrm{~mm} / \mathrm{kyr}$, but bigger at any water flow rates of $1.1 \mathrm{~mm} / \mathrm{yr}$, $1.5 \mathrm{~mm} / \mathrm{yr}$, and $2.0 \mathrm{~mm} / \mathrm{yr}$ compared to the reference case $\left(q_{w}=0.7 \mathrm{~mm} / \mathrm{yr}\right)$, which are consistent with our consideration. The biggest hydrate saturation at water flow rate of $2.0 \mathrm{~mm} / \mathrm{kyr}$ is $37 \%$ in the modeling and still smaller than the peak values computed by chloride and logging data, and further the saturation curve in the middle depth is higher than the values calculated by the logging data. The results suggest that the hydrate distribution at site $\mathrm{SH} 2$ in Shenhu Area can not be well reproduced by altering water flow rate in the modeling.

\section{A new overlook on the hydrate accumulation}

The simulations above reveal the hydrate system is significantly influenced by sedimentation and water flow as an agent of gas supply. But the simulated curves do not satisfy the hydrate saturation values calculated by water salinity and logging data. This might be because hydrate saturation grew from zero in the

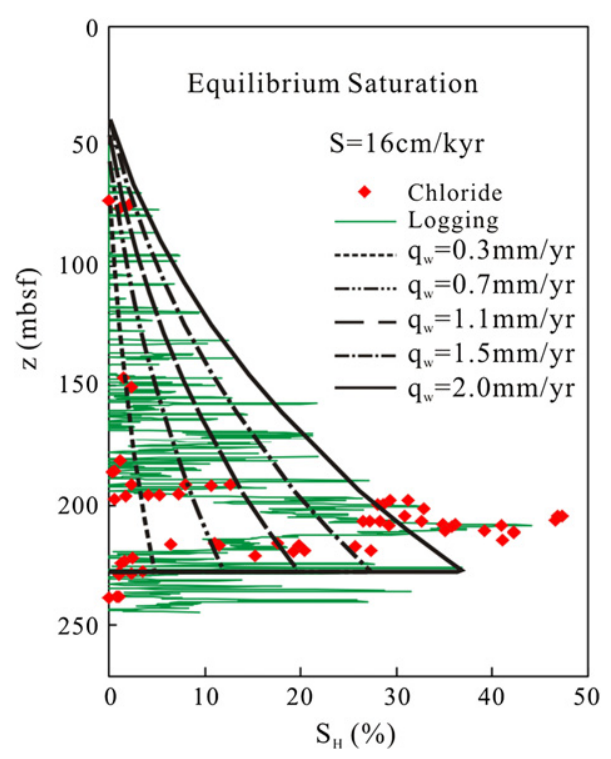

Figure 8. Effect of water flow rate to the hydrate accumulation at the constant seafloor depositional rate of $16 \mathrm{~cm} / \mathrm{kyr}$. The equilibrium saturations at the water flow rates and the constant seafloor depositional rate are less than the hydrate contents determined by Chloride and Logging. modeling and the two controlling parameters are limited to the current geologic conditions. Although sedimentation rate in geologic scale can be estimated by sediment dating, water flow rate evaluated by current porewater chemistry may only represent fluid flow in a short period at present. The water flow rate in Shenhu area might have experienced some changes, especially be influenced by the tectonic activities at 1.5 Myrs before present. The rapid water flow during the tectonic activities might result in concentrated hydrate in fractured sediment. The subsequent hydrate accumulation developed from the old hydrate. The hydrate preexisting in the fractured sediment must have substantial impact on hydrate evolution and current distribution. Thus the modeling on hydrate accumulation with the two parameters should be based on the former hydrate saturation.

Methane hydrate had resided in the old sediment and the following evolution of hydrate was under conditions of the average sedimentation rate and the current water flow rate. In the modeling an initial value of hydrate saturation is given to represent the old hydrate. Many initial values were experimented for obtaining a modeled curve matching the hydrate distribution. Figure 9 shows that the saturation values are well enveloped by the curves modeled at initial saturation values $S_{H, i}=20-22 \%$. The best curve occurs at $t=1.5$ Myrs, which means that the newly developed hydrate started $\sim 1.5$ Myrs before present. This time point is consistent with the end of last tectonic activity. The modeling suggests that the faulted sediment pores were filled with hydrate of $20-22 \%$ fraction at the end of last tectonic activity and the subsequent 1.5 Myrs evolution produced the current hydrate feature at Shenhu Area.

Figure 9 also indicates hydrate resource is reducing. Because of the rapid seafloor deposition, hydrate formation in newly deposited sediment can not offset hydrate dissociation at the base of GHSZ. The equilibrium hydrate saturation is determined by the current sedimentation rate and water flow rate, thus the ultimate hydrate feature is predicable and shown in Figure 6 . The current hydrate occurrence is just one scenario of whole evolution. The model result implies that the hydrate at the site has been consuming. The hydrate saturation will be less than $20 \%$ when the hydrate system reaches dynamic balance completely 0.5 Myrs late under the current sedimentation and fluids flow.

\section{Discussion}

The hydrate accumulation at Shenhu Area is studied by the equilibrium hydate formation model with two controlling parameters of sedimentation and water flow rates. The model is still incomplete and extremely simplified, and many aspects on hydrate evolution require discussion.

The above calculations showed that sedimentation could cause hydrate dissolution at the base of hydrate layer. New sediment superposes on seafloor and old sediment at the base of GHSZ exits downwards. But thickness of the GHSZ keeps generally invariant since change in temperature and pressure should be small in the short geologic period. Rapid sedimentation rates mean faster hydrate dissociation at the base of GHSZ. Thus hydrate amount will decrease if gas supply is insufficient, and hydrate in the GHSZ will be renewed continually.

The modeling also indicates that increasing water flow rate could promote hydrate growth. The thermodynamic conditions of hydrate formation were defined by the solubility phase diagram. Hydrate accumulation was related to water flow rate. The overall gas precipitated as hydrate was assumed to be simply from deep source fluids, and in-situ methane generation was not considered in the model. The simplification is reasonable for fine-grained sediments below seafloor in which organic matter is poor within GHSZ. 

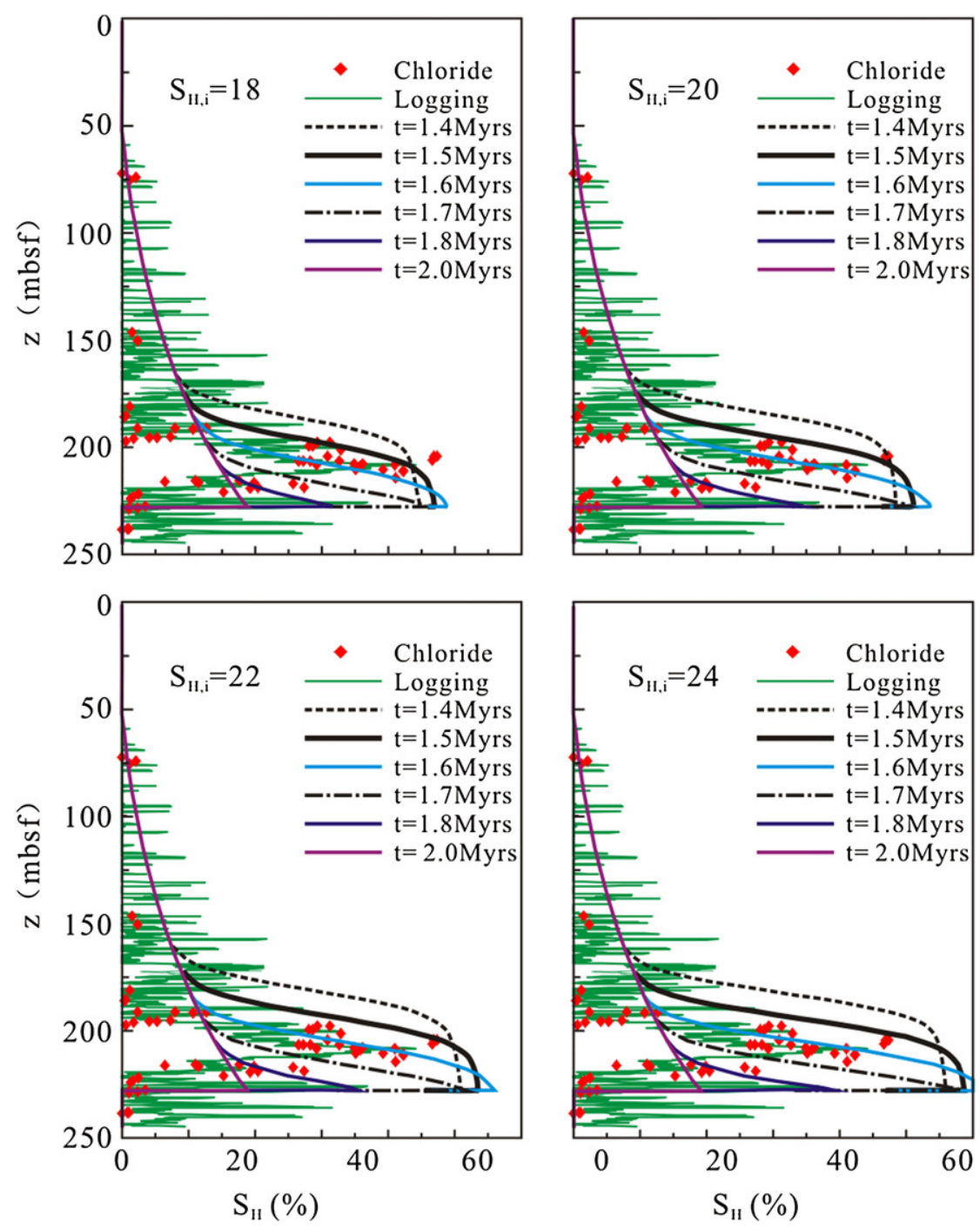

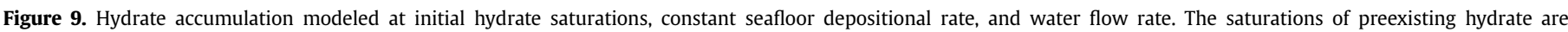
respectively $18 \%, 20 \%, 22 \%$, and $24 \%$. The seafloor depositional rate is $16 \mathrm{~cm} / \mathrm{kyr}$, the water flow rate is $0.7 \mathrm{~m} / \mathrm{kyr}$.

The methane hydrate at Shenhu Area is decaying. In this paper we speculate that the "ancient" hydrate had been enriched in the fractured sediment, and the speedy deposition led to hydrate decomposition at the base of GHSZ. After the faulted sediment was covered by fine-grained sediment, deep fluids could not transmit effectively into the new sediment to form hydrate. The modeling indicated that old hydrates of $20-22 \%$ saturation preexisted in the "ancient" sediment, but formation process of the "ancient" hydrate was not explicated in the context. However, it was still possible that the Shenhu hydrate evolved as the pattern proposed in this paper, because the complicated faults as fluid pathways supported quick fluid flow and formation of concentrated hydrate.

The development pattern of methane hydrate in Shenhu Area can also be verified by temporal coupling. The last tectonic activity happened in 2.0-1.5 Myrs before present, and the sediment age at the base of GHSZ was identified to be 1.58 Myrs, which suggested that the hydrate formation started at the end of tectonic activity in the faulted sediment. It was accessible that the hydrate accumulated in the seeping system at the end of tectonic activity when fluid flow became small and sediment temperature was more feasible for hydrate formation. The evolution time in the modeling at the parameters was $\sim 1.5$ Myrs and consistent with the age of faults. The consistency conforms our understanding that the Shenhu hydrate have developed from the "ancient" hydrate formed in fractured sediment.

\section{Conclusion}

This study constructed a model on dynamics of a marine hydrate reservoir, and numerically described sedimentation, fluid flow, and equilibrium hydrate formation. The controlling parameters in the model were sedimentation rate and water flow rate. The model was used to study gas hydrate accumulation at drilling site $\mathrm{SH} 2$ in Shenhu Area of the South China Sea. The hydrate growth reached equilibrium in the modeling at time less than the sediment age and the modeled curves of hydrate saturation were evidently less than the saturations calculated by salinity and logging data. Decreasing sedimentation rate or increasing water flow rate could promote hydrate growth based on the model results, but still could not reproduce the observed hydrate evolution. We suggest that "ancient" hydrate of high saturation formed in the faulted sediment, the current hydrate was developed by inheriting the "ancient" hydrate under the conditions of sedimentation and water flow. This new overlook perfectly produced the hydrate 
accumulation at site $\mathrm{SH} 2$, and also implied that the hydrate had been degenerating.

\section{Acknowledgment}

This study was supported by NSFC (41076037), Bureau of International Co-operation, Chinese Academy of Science (KZCX2YW-GJ03), NSFC-Guangdong Joint Science Foundation of China (U0933004), 973 Program (2009CB219508), and Guangzhou Marine Geological Survey. We thank Dr. Hailong Lu (Steacie Institute for Molecular Sciences) for stimulating discussions, Dr. Dong Feng (Louisiana State University) for his review and comments. The manuscript was substantially improved by the suggestions of the reviewer and editor.

\section{References}

Athy, L.F., 1930. Density, porosity, and compaction of sedimentary rocks. AAPG Bulletin 14, 1-24.

Berner, R.A., 1980. Early Diagenesis: a Theoretical Approach. Princeton University Press, Princeton, New Jersey. 241 p.

Bhatnagar, G., Chapman, W.G., Dickens, G.R., et al., 2007. Generalization of gas hydrate distribution and saturation in marine sediments by scaling of thermodynamic and transport processes. American Journal of Science 307, 861-900.

Chen, D., Cathles, L.M., 2003. A kinetic model for the pattern and amounts of hydrate precipitated from a gas steam: application to the Bush Hill vent site, Green Canyon Block 185, Gulf of Mexico. Journal of Geophysical Research 108 (B1), 2058. http://dx.doi.org/10.1029/2001JB001597.

Collett, T.S., 2002. Energy resource potential of natural gas hydrates. AAPG Bulletin 86, 1971-1992.

Davie, M.K., Buffett, B.A., 2001. A numerical model for the formation of gas hydrate below the seafloor. Journal of Geophysical Research 106, 497-514.

Davie, M.K., Buffett, B.A., 2003a. Sources of methane for marine gas hydrate: inferences from a comparison of observations and numerical models. Earth and Planetary Science Letters 206 (1), 51-63.

Davie, M.K., Buffett, B.A., 2003b. A steady state model for marine hydrate formation: constraints on methane supply from pore water sulfate profiles. Journal of Geophysical Research 108 (B10), 2495. http://dx.doi.org/10.1029/ 2002JB002300.

Davie, M.K., Zatsepina, O.Y., Buffett, B.A., 2004. Methane solubility in marine hydrate environments. Marine Geology 203, 177-184.

Dickens, G.R., 2003. Rethinking the global carbon cycle with a large, dynamic and microbially mediated gas hydrate capacitor. Earth and Planetary Science Letters 213, 169-183.

Duan, Z.H., Moller, N., Greenberg, J., Weare, J.H., 1992. The prediction of methane solubility in natural waters to high ionic strength from 0 to $250^{\circ} \mathrm{C}$ and from 0 to 1600 bar. Geochimica et Cosmochimica Acta 56, 1451-1460.

Gibson, R.E., 1958. The progress of consolidation in a clay layer increasing in thickness with time. Geotechnique 8, 171-182.

Ginsburg, G., Soloviev, V., Matveeva, T., Andreeva, I., 2000. Sediment grain-size control on gas hydrate presence, sites 994, 995, and 997. In: Paull, C.K., Matsumoto, R., Wallace, P.J., Dillon, W.P. (Eds.), Proceedings of the Ocean Drilling Program, Scientific Results, vol. 164, pp. 237-245.
Guan, J., Liang, D., Wu, N., Fan, S., 2009. The methane hydrate formation and the resource estimate resulting from free gas migration in seeping seafloor hydrate stability zone. Journal of Asian Earth Sciences 36, 277-288.

Haacke, R.R., Westbrook, G.K., Riley, M.S., 2008. Controls on the formation and stability of gas hydrate-related bottom-simulating reflectors (BSRs): a case study from the west Svalbard continental slope. Journal of Geophysical Research 113, B05104. http://dx.doi.org/10.1029/2007JB005200.

Hinrichs, K.U., Boetius, A., 2002. The anaerobic oxidation of methane: new insights in microbial ecology and biogeochemistry. In: Wefer, G., Billet, D., Hebbeln, D. et al. (Eds.), Ocean Margin Systems. Springer-Verlag, Heidelberg, pp. 457-477.

Joye, S.B., Boetius, A., Orcutt, B.N., et al., 2004. The anaerobic oxidation of methane and sulfate reduction in sediments from Gulf of Mexico cold seeps. Chemical Geology 205, 219-238.

Liu, X., Flemings, P.B., 2006. Passing gas through the hydrate stability zone at southern Hydrate Ridge, offshore Oregon. Earth Planet. Sci. Lett. 241, 211-226.

Liu, X., Flemings, P.B., 2007. Dynamic multiphase flow model of hydrate formation in marine sediments. Journal of Geophysical Research 112, B03101. http:// dx.doi.org/10.1029/2005JB004227.

McDonnell, S.L., Max, M.D., Cherkis, N.Z., Czarnecki, M.F., 2000. Tectono-sedimentary controls on the likelihood of gas hydrate occurrence near Taiwan. Marine Petroleum and Geology, 929-936.

Milkov, A.V., Sassen, R., 2003. Preliminary assessment of resources and economic potential of individual gas hydrate accumulations in the Gulf of Mexico continental slope. Marine and Petroleum Geology 20, 111-128.

Milkov, A.V., 2004. Global estimates of hydrate-bound gas in marine sediments: how much is really out there? Earth-Science Reviews 66, 183-197.

Rempel, A.W., Buffett, B.A., 1997. Formation and accumulation of gas hydrate in porous media. Journal of Geophysical Research 102, 10151-10164.

Sloan, E.D., 1998. Clathrate Hydrates of Natural Gases. Marcel Dekker, New York. $726 \mathrm{p}$.

$\mathrm{Su}, \mathrm{Z}$., Chen, D., 2007. Calculation of methane hydrate solubility in marine environment and its constraints on gas hydrate occurrence. Chinese Journal of Geophysics 50 (5), 1332-1340.

Sultan, N., Cochonat, P., Foucher, J.P., Mienert, J., 2004. Effect of gas hydrates melting on seafloor slope instability. Marine Geology 213, 379-401.

Terzaghi, K., 1943. Theoretical Soil Mechanics. Wiley, New York. 528 p.

Treude, T., Niggemann, J., Kallmeyer, J., et al., 2005. Anaerobic oxidation of methane in the sulfate-methane transition along the Chilean continental margin. Geochimica et Cosmochimica Acta 69, 2767-2779.

Wang, P., Prell, W., Blum, P., 2000. Ocean drilling Program Leg 184 Scientific Prospectus South China sea, site 1144, 184. In: Wang, P., Prell, W.L., Blum, P. (Eds.), Proceedings of the Ocean Drilling Program, Initial Reports, Ocean Drilling Program, College Station, TX, pp. 1-97.

Wang, X., Hutchinson, D.R., Wu, S., Yang, S., Guo, Y., 2011. Elevated gas hydrate saturation within silt and silty clay sediments in the Shenhu area, South China Sea. Journal of Geophysical Research 116, B05102. http://dx.doi.org/10.1029/ $2010 J B 007944$.

Wu, N., Yang, S., Wang, H., Liang, J., 2009. Gas-bearing fluid influx sub-system for gas hydrate geological system in Shenhu Area, Northern South China Sea. Chinese Journal of Geophysics 6, 1641-2165 (in Chinese with English abstract).

Wu, N., Yang, S., Zhang, H., Liang, J., Wang, H., Lu, J., 3-6 May 2010. Gas Hydrate System of Shenhu Area, Northern South China Sea: Wire-line Logging, Geochemical Results and Preliminary Resources Estimates. OTC 20485, 2010 Offshore Technology Conference, Houston, Texas, U.S.A..

$\mathrm{Xu}, \mathrm{W}$., Ruppel, C., 1999. Predicting the occurrence, distribution, and evolution of methane gas hydrate in porous marine sediments. Journal of Geophysical Research 104, 5081-5096. 